\title{
Mulheres da Várzea, uma análise da participação das mulheres no processo produtivo na Ilha do Baixio
}

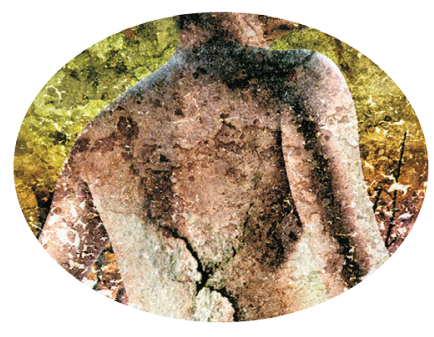

Cleonice Oliveira de Andrade* Kátia Helena Serafina Cruz Schweickeardt ${ }^{* *}$

\section{Resumo}

Este artigo tem como objetivo descrever, a partir da percepção das mulheres da ilha do Baixio, como se dá a sua inserção no processo produtivo local e analisar as estratégias dessas mulheres, visando à construção de processos de desenvolvimento mais sustentáveis a partir das mudanças sociais com a implantação do Projeto de Assentamento Agroextrativista pelo Incra. Em termos gerais, neste artigo pretende-se descrever etnograficamente a participação das mulheres na construção das organizações sociais do PAE da ilha, assim como suas atividades nos processos produtivos, focando especificamente na descrição e análise das mudanças sociais causadas pela transformação da ilha do Baixio em um projeto de Assentamento Agroextrativista de várzea pela percepção das mulheres que lá vivem; na descrição das principais atividades desenvolvidas pelas mulheres da ilha do Baixio, a partir da dinâmica do seu cotidiano; e na identificação das formas de organização social, formais e informais existentes na ilha do Baixio e analisar como se dá a participação das mulheres nessas organizações; assim como na análise da contribuição da associação das mulheres da ilha do Baixio no processo produtivo do PAE.

\footnotetext{
* Graduanda em Ciências Sociais na Universidade Federal do Amazonas - UFAM, Brasil.

** Doutora em Sociologia e Antropologia pela Universidade Federal do Rio de Janeiro (UFRJ). Professora Adjunta do Departamento de Ciências Sociais e do Programa de Pós-Graduação em Sociologia - PPGS da Universidade Federal do Amazonas. E-mail: katia.helena@uol.com.br
} 
Palavras-chave: várzea; processo produtivo; mulheres da floresta; projeto de assentamento agroextrativista.

\begin{abstract}
This article aims to describe, from the perception of women Ilha do Baixio, how is their integration into the local productive process and analyze the strategies of these women, in order to build more sustainable development processes from the social changes with the implementation of the Settlement Project Agroextractive by Incra. In general terms, this article aims to describe ethnographically women's participation in the construction of social organizations PAE of the island, as well as its activities in the production process, specifically focusing on the description and analysis of the social changes caused by the transformation of Ilha da Baixio in Project Agroextractive Settlement floodplain by the perception of women who live there, in the description of the main activities undertaken by women island shoal, from the dynamics of your everyday life, and the identification of the forms of social organization, the existing formal and informal island Bog and analyze how is women's participation in these organizations, as well as analysis of the contribution of the association of women Ilha do Baixio in the production process of the PAE.
\end{abstract}

Keywords: floodplain; production process; forest women; settlement project agroextractivist.

\title{
Introdução
}

A ilha do Baixio é formada por florestas inundadas onde predomina o ecossistema de várzea. Esse ecossistema é caracterizado por uma grande concentração de biodiversidade e por expressiva variação no nível das águas, que oscila entre $8 \mathrm{~m}$ na estação seca e $15 \mathrm{~m}$ na estação das chuvas (AYRES, 1993).

As épocas de cheia, vazante, seca e enchente compõem um ciclo anual bem marcado por mudanças nas condições de transporte, no acesso à água, nos alimentos disponíveis, nas produções extrativas, chamadas em muitas regiões da Amazônia de “fábricos” (LIMA, 2005: 350). 
O ciclo natural da várzea e, consequentemente, o ciclo anual das atividades de subsistência das atividades de subsistência humanas, não depende, como na terra firme, da alternância de estações seca e chuvosa, mas do regime fluvial. A agricultura é praticada de setembro a abril no solo enriquecido pelo limo, anualmente renovável. Em virtude da grande produtividade da agricultura, da caça e da pesca e das técnicas de armazenamento e conservação de alimentos que as populações da várzea desenvolveram (e que não se encontram ou não acessíveis em terras firmes).

O ecossistema da várzea encontra-se circunscrito pela dinâmica dos ciclos das águas: o período do plantio pode ser favorecido ou prejudicado; as configurações dos lagos e paranás, com suas singulares vegetações que se relacionam com a produção e reprodução da fauna aquática; os aningais e chavascais, com suas respectivas vegetações; a criação animais-suínos, aves e gado (este necessitando de grandes quantidades de forrageiras). Esses são alguns dos impasses que o camponês que habita a várzea amazônica enfrenta, ciclicamente durante sua vida. Aproveitando-se desse movimento cíclico de fertilização da terra, o camponês e sua família têm posto em prática seu trabalho na várzea, fecundando a terra e manobrando sua biodiversidade (WITKOSKI, 2010).

Muitas famílias possuem canteiros suspensos em suas casas, para o consumo na época da cheia, pois é nesse período que eles mais sofrem com a escassez das hortaliças e frutas. Além da agricultura, a pesca também tem papel fundamental na vida dessas pessoas, elas pescam o ano todo, tanto na cheia como na vazante, sempre tem o peixe para o consumo da família ou na maioria das vezes também para venda.

As mulheres têm conquistado alguma visibilidade em vários pontos da Amazônia brasileira por meio da ampliação de suas bases organizativas. Suas experiências têm sido variadas, independente do tipo de sociedade nas quais elas estão inseridas. Apesar de ainda sofrerem preconceitos, sua resistência tem produzido muitas transformações, tanto em termos de inserção nos processos produtivos como quanto nas relações de poder (SIMONIAN, 2001).

As instituições, como Igreja Católica e organizações sindicais, tanto nos recursos proporcionados por meio de projetos quanto na orientação política, vêm incentivando a participação dessas mulheres nos planos de desenvolvimento. A identificação do cotidiano, tecido por seus modos de vida, pode ajudar a 
entender aspectos fundamentais de compreensão singular dessas mulheres sobre o território. Para Castro (Apud SIMONIAN, 2001), a compreensão da sua concepção de territorialidade só pode ser percebida no interior das relações que estruturam e organizam sua vida coletiva e da reprodução social do grupo, no âmbito das quais as mulheres têm desempenhado historicamente papel fundamental.

$\mathrm{Na}$ comunidade pesquisada, o processo de produção na várzea tem participação das mulheres no cultivo das hortaliças, elas também têm canteiros suspensos com suas plantações de cebolinhas, couve, alface, entre outros, para o consumo da família na época da cheia, pois toda a produção é retirada antes da chegada da enchente para a venda e também para o consumo.

Segundo Simonian (2001), a diversidade de perspectivas na participação das mulheres em programas de desenvolvimento é grande, mesmo que em diversos contextos sem muita visibilidade. $\mathrm{Na}$ literatura, há diversos exemplos da relação íntima das mulheres com os recursos naturais na Amazônia brasileira (KAINER, DURYEA; SIMONIAN, 1988), onde as mulheres têm grande controle sobre os conhecimentos da biodiversidade (SCHWEICKARDT apud 2010).

Em face disso, muitos trabalhos relacionados às questões de gênero entre grupos sociais ligados ao campo no Brasil estiveram voltados para a esfera do trabalho, visando considerar as inúmeras atividades desenvolvidas pela mulher no lar e nas pequenas propriedades agrícolas, como forma de torná-las visíveis e mais valorizadas (PAULILO \& CYRINO, 2009).

Pensar uma dada realidade social a partir da Sociologia do gênero, mesmo que se constituindo num campo de investigação científico conflitivo e pouco consensual (CYRINO, 2009), vem cada vez mais ganhando legitimidade no espaço acadêmico. Autoras como Scott (1991) há muito defendem que o gênero é uma categoria analítica que estrutura o sistema perceptivo dos indivíduos e remete à organização concreta de toda vida social.

O discurso em torno da noção de desenvolvimento sustentável, a despeito de sua ambiguidade, tem trazido à tona formas tradicionais de trabalho, agora tornadas visíveis com base numa economia de recursos naturais.

Uma análise mais cuidadosa das formas de cumprir um calendário agroextrativo por parte das mulheres, dentro do qual se inclui a agricultura de mandioca e de outras raízes e frutos, a pesca, a caça, o manejo de espécies 
extrativas, coleta de sementes oleaginosas revelam formas de produção e de organização social interna complexa e singular do ponto de vista social e cultural.

Nessa perspectiva, segundo Schweickardt (2010), construir um olhar mais interrogativo sobre o conjunto dos atores sociais da floresta, no interior da Amazônia, dando especial destaque à voz e à percepção das mulheres no processo produtivo na comunidade de Santa Luzia, pode nos tornar capazes de captar outras relações lógicas.

\section{A cultura da juta e malva}

Segundo alguns relatos feitos pelos moradores da ilha do Baixio, nem sempre as pessoas viveram do cultivo das hortaliças. Num passado recente, elas cultivavam juta e malva como principal atividade econômica, mas também plantavam milho, mandioca e feijão-de-praia, a pesca e a caça de jacaré eram para a comercialização de couro que ajudava na renda da família. A cultura de juta e malva deu início com a imigração japonesa na Amazônia.

Segundo Homma (2010), a imigração japonesa no Estado do Amazonas tem origem muito antes da data oficial de 18 de junho de 1908, com a chegada do navio Kasato Maru, no porto de Santos, cujo centenário foi comemorado em 2008.

Com a crise da borracha, a economia da Amazônia ficou, praticamente, estagnada no período de 1920 a 1940. Com outros produtos extrativos tentouse reequacionar o desequilíbrio da economia, entre eles destacou-se a extração do óleo essencial de pau-rosa e a castanha-do-pará. Nenhum desses produtos, porém, conseguiu recuperar a primazia da seringueira.

As atividades agrícolas e a população rural se distribuíram ao longo dos rios, onde o transporte fluvial era, e ainda é, o mais importante. A introdução da lavoura da juta marcou a agricultura nas várzeas dos Estados do Amazonas e Pará, com o envolvimento de mais de 60 mil famílias, no seu auge na década de 1960. Outro aspecto da juta foi de provocar a valorização da malva, que era uma erva daninha cujas sementes ficam conservadas no solo por vários anos, à espera do momento oportuno para a germinação (HOMMA, 2010).

O sucesso da cultura da juta nas várzeas dos Estados do Amazonas e Pará trouxe uma prosperidade momentânea para os imigrantes japoneses e respeito 
por parte dos brasileiros. Ocorreu um rápido processo de democratização dessa cultura com a sua difusão feita pelos ribeirinhos amazonenses e paraenses (HOMMA et. al., 2011).

Em razão da baixa lucratividade, porém, e por ser altamente intensiva a mão de obra e por ter um processo de trabalho extremamente perigoso, com muitos transtornos, principalmente para a saúde dos trabalhadores, aos poucos esses trabalhadores da juta foram deixando a atividade. Algumas mulheres relataram que até hoje sofrem com as consequências do trabalho da juta e malva, pois elas disseram que era um trabalho muito pesado, pois trabalhavam o tempo todo dentro d'água, e com o passar do tempo elas acabavam adoecendo.

A plantação da juta é substituída pela plantação de hortaliças na ilha do Baixio por volta dos anos de 1980, por incentivo do Instituto de Desenvolvimento Agropecuário e Florestal Sustentável do Estado do Amazonas - Idam, segundo alguns relatos dos moradores da comunidade, todos ficaram muito felizes, pois cada um podia fazer o próprio roçado contribuindo assim com a renda da família e para seu consumo. Eles vendem como principal produto a melancia, mas também as hortaliças como couve, repolho, alface, tomate, pimentão, feijão-de-corda, cebolinha, entre outros. Hoje, a economia de Santa Luzia da ilha do Baixio é baseada na agricultura.

\section{O processo produtivo da ilha do Baixio e a questão agrária}

Historicamente, a orientação das políticas governamentais se fez no sentido do uso intensivo da terra e dos recursos naturais. Tanto os empreendimentos agropecuários quanto os projetos convencionais de assentamento de pequenos produtores, meta fundamental das políticas executadas pelo Incra na Amazônia entre a década de 1970 e o final da década de 1990, foram desenhados a partir do modelo de uso intensivo dos recursos naturais, sobretudo florestas, solo e água (SCHWEICKARDT, 2011):

A Amazônia, que abriga imensa bacia hidrográfica, ainda hoje expõe, nas calhas de seus rios, uma diversidade de modos de vida, relacionados não apenas ao uso e posse das áreas de terra firme, mas também ao uso e as formas de domínio sobre as áreas de várzeas (FRAXE, 2000; LIMA, 
2005; WITKOSKI, 2007) e sobre as águas nas quais seus habitantes praticam invariavelmente a pesca, conjugada de vários modos a outras atividades econômicas. Não só em terra firme, mas também nas áreas de várzeas e sobre as águas, constroem seus caminhos, suas casas e escolas flutuantes (SCHWEICKARDT, 2011: 186).

Segundo Schweickardt (2011), a ideia subjacente a toda a estratégia de territorialização, que já vinha sendo posta em prática desde os anos de 1930, com a implantação das Colônias Agrícolas Nacionais (Canas) e passou a ser sistematicamente implantada a partir dos governos militares, era a de converter a natureza pensada como improdutiva de uma região imaginada como demograficamente vazia e economicamente desintegrada do restante do país, convertendo-a em áreas produtivas voltadas para o mercado.

A Amazônia começava a se transformar num "imenso laboratório de políticas e projetos que, de uma forma ou de outra, tentam compatibilizar a presença dos habitantes com algum tipo de medidas visando à conservação dos ecossistemas em que vivem" (ESTERCI apudESTERCI e SCHWEICKARDT, 2011). Segundo a autora, a implementação desses projetos e políticas levou a demarcação de uns espaços, a redefinição e reclassificação de outros, assim como a reclassificação dos próprios segmentos sociais afetados (SCHWEICKARDT apud ESTERCI e SCHWEICKARDT, 2011):

Partilhando do conceito de Leite Lopes (2004), poderíamos caracterizar este processo como a "ambientalização" da gestão territorial na Amazônia. Mais que a definição de um fenômeno moderno, o conceito diz respeito, entre outras coisas, ao modo como os diversos atores (trabalhadores, empresários) e, sobretudo o Estado e suas agências, passam a utilizar a questão ambiental como repertório de expressão de seus interesses e reivindicações (SCHWEICKARDT, 2010: 310).

Segundo Schweickardt (2010), o Incra, espelhando-se em outra categoria de Unidade de Conservação, criou uma modalidade de assentamento voltado para o "desenvolvimento sustentável", o Projeto de Desenvolvimento Sustentável - PDS, num paralelo com a Reserva de Desenvolvimento 
Sustentável - RDS. O primeiro criado no Brasil e no Estado do Amazonas, o PDS Morena, no município de Presidente Figueiredo. Só que diferente da RDS, o PDS visava ser um meio-termo entre o Projeto de Assentamento convencional, onde se tinha a formação do assentamento com populações de diferentes procedências e o loteamento individual, e o Projeto Agroextrativista, onde a população, preferencialmente, seria local, com experiência na atividade extrativista e no uso coletivo da terra.

\section{Assentamentos Rurais nas áreas de várzea}

A ilha do Baixio foi transformada em Projeto de Assentamento do Incra, no ano 2007, embora as mulheres entrevistadas declarassem desconhecer a data precisa. Elas só sabem dizer que o Projeto de Assentamento do Incra trouxe muitos benefícios para muitas famílias, um exemplo que elas citam é que muitas famílias moravam juntas. Agora, com o Projeto Filhos Casados, já tem a casa própria, com exceção de alguns que não conseguiram, segundo elas, porque têm renda fixa como aposentadoria, ou trabalha com remuneração. Mas para a maioria que vive só da agricultura, a casa do Incra foi um apoio importante. As mulheres entrevistadas também não souberam informar quanto tempo levariam para pagar essas casas e nem sabiam quanto elas custavam. Essas casas são construídas em madeira, mas são bem feitas, a estrutura é feita para área de várzea, muitas delas com ar-condicionado, uma visão diferente daquilo que imaginava que tinha na comunidade.

Reforma agrária e assentamentos são expressões habitualmente usadas com o mesmo significado. Fica difícil estabelecer onde uma se insere na outra, onde uma começa e a outra termina. Uma possível distinção de ordem prática está em considerar a reforma agrária como regularização fundiária, no sentido de torná-la mais equânime. Já o assentamento compreenderia, basicamente, as ações de natureza prática que se iniciaria com a seleção dos beneficiários da reforma agrária e se encerraria no momento em que eles tomassem posse do lote que lhes tenha sido destinados (PALMEIRA, 1994).

Como a maioria das autarquias federais, sobretudo as originadas da ditadura militar, o Incra, até o final da década de 1990, teve o poder de definição de suas políticas concentrado na administração central, em Brasília, ignorou os particularismos regionais e se impôs ao planejamento estadual 
e municipal. Tratava-se de preparar as condições para a empresa capitalista (SCHWEICKARDT, 2011):

A partir dos anos de 1980, no entanto, ficou evidente o fracasso dos grandes projetos agropecuários, com base no modelo desenvolvimentista na região, e o Estado retirou, então, o "suporte ou incentivo à agropecuária regional para otimizar os resultados globais da produção" (COSTA, 2000), o que, de certa forma, veio ao encontro das preocupações ambientais com a Região, que já começavam a despontar (Apud SCHWEICKARDT, 2011: 187).

$\mathrm{Na}$ fase de assentamento ocorre, às vezes, uma relação de "estranheza" com a terra que é atribuída aos assentados. Ao ser cadastrada, a família de trabalhadores rurais passa a sujeitar-se a uma série de regras fixadas para ela e não por ela. A escolha das culturas, a construção da moradia e da agrovila, a forma de se explorar a terra são colocadas pelos "outros". O fato de terem postos como iguais no momento da luta não significa necessariamente sua disposição de estruturar-se coletivamente para a organização social da produção, mesmo porque a perspectiva de construção de uma coletividade rural de produtores em cooperação não é necessariamente produto da vontade dos trabalhadores, resposta a uma decisão de modelo cooperativo forjado nas instâncias do poder (FERRANTE, 1994).

Em termos de política fundiária, as áreas de várzeas estão sob a jurisdição do Serviço de Patrimônio da União - SPU, a quem caberia arrecadar as chamadas "terras devolutas" e matriculá-las em nome da União concedendo o usufruto aos moradores, segundo restrições em função da fragilidade ecológica daquele ecossistema (SCHWEICKARDT, 2010):

Como a representação de tal ente da federação no Amazonas não dispõe de quadro técnico suficiente para atuar na regularização fundiária das imensas faixas de várzea do Estado do Amazonas e nem se dispõe de recursos orçamentários e financeiros para trabalhar com tais populações, por iniciativa dos gestores orçamentários e financeiros para trabalhar com tais populações, por iniciativa dos gestores dos dois órgãos federais, SPU e Incra, 
no Amazonas, foi firmado um Acordo de Cooperação Técnica para que o Incra pudesse atuar nas referidas áreas de várzea com os recursos do programa nacional de reforma agrária (SCHWEICKARDT, 2010: 6).

Desse modo, a ilha do Baixio foi transformada no Projeto de Assentamento Agroextrativista da ilha do Baixio e seus moradores da várzea tornaram-se assentados do Incra.

\section{Gênero e produção na várzea}

$\mathrm{Na}$ construção da categoria "trabalho", seja ele remunerado ou não, sempre se mostrou relevante para o pensamento feminista. Considerar trabalho as inúmeras atividades desenvolvidas pela mulher no lar e nas pequenas propriedades agrícolas foi uma forma de torná-las visíveis e mais valorizadas. Quanto ao trabalho remunerado, ele foi considerado fundamental, pois em uma sociedade em que tudo se compra, o acesso da mulher a alguma forma de renda própria poderia torná-la mais independente do marido e mais participante nas decisões que envolvem tanto o grupo doméstico como a sociedade mais ampla. Quatro décadas de feminismo não diminuíram a importância dessa categoria. É ela que está no cerne de uma das principais conquistas dos movimentos de mulheres agricultoras, que junto com outros movimentos sociais ligados ao campo, lutou para que as esposas envolvidas na produção agrícola familiar fossem consideradas "produtoras rurais" e não "do lar" (PAULILO, 2009):

Na história recente da Amazônia, muito se tem falado sobre a importância feminina nos processos de desenvolvimento. De fato, além de sua colaboração fundamental, em termos do processo de reprodução social e biológica, a contribuição das mulheres nos processos de produção agrícola, extrativista e artesanal local tem sido largamente relevada, especialmente entre mulheres indígenas (CHERNELA, 1986, RAVENA, 1996, VELTHEM, 1995) e entre as extrativistas (SIMONIAN, 2001; ALMEIDA, 1995) (SCHWEICKARDT apud, 2010). 
Durante a realização da pesquisa observou-se que as mulheres da comunidade procuram participar de todas as atividades, elas são donas de casa, ajudam na agricultura, trabalham na escola, outras são aposentadas, mas não deixam de dar sua contribuição para ajudar a comunidade a se desenvolver cada vez mais, não esquecendo, também, a grande contribuição e união dessas mulheres nas organizações das festas sociais da comunidade. Nos últimos anos, tem crescido o reconhecimento da participação de mulheres, seja na esfera do trabalho, seja na esfera política. A Conferência de Beijing, promovida pela ONU em 1995, foi transformada, segundo alguns autores (ABRAMOVAY, LERNER, 1995), em um marco importante para os avanços teóricos, mesmo setores importantes da sociedade em geral ainda resistam em confirmar na prática as resoluções acordadas (SIMONIAN, 2001). Na comunidade pesquisada, o processo de produção na várzea tem participação das mulheres no cultivo das hortaliças, elas também têm canteiros suspensos com suas plantações de cebolinhas, couve, alface, entre outros, para o consumo da família na época da cheia, pois toda a produção é retirada antes da chegada da enchente para a venda e também para o consumo.

\section{A participação das mulheres na cultura das hortaliças}

No cultivo das hortaliças, segundo algumas entrevistas realizadas com as mulheres da comunidade, elas relataram que todos da família contribuem, elas plantam cebolinha, pepino, tomate, pimentão, jerimum, quiabo, maxixe, feijãode-corda, couve, alface, melancia, entre outros. A maior parte da produção das hortaliças é vendida para a cidade de Manaus com grande destaque a melancia, apesar da ilha do Baixio pertencer ao município de Iranduba.

Uma das maiores dificuldades que elas diziam ter era o meio de transporte para vender suas verduras, pois tinham de levar até Iranduba, depois pegar a balsa até Manaus, muitos vendem para os atravessadores, tornando assim as vendas das verduras mais baratas, chegando às feiras de Manaus com um preço bastante elevado. Agora, com a ponte sobre o rio Negro finalizada, o acesso a Manaus vai ficar muito mais rápido, os agricultores poderão ir direto para Manaus e vender suas hortaliças por um preço mais justo.

Em entrevista com dona Rondineia, ela relata um pouco sobre a renda obtida com a venda das hortaliças: 
Não tem uma renda fixa. Varia, quem vive de agricultura não tem renda fixa, tem semana que a verdura é vendida de um preço, e tem semana que é vendida de outro preço, tem mês que chega a menos de um salário mínimo, tem mês que chega a mais de um salário mínimo, principalmente porque a verdura é vendida para atravessadores (Entrevista com dona Rondineia, comunidade Santa Luzia da ilha do Baixio, 7/7/2011).

\section{Festas na ilha do Baixio}

A ilha do Baixio realiza algumas festas importantes na comunidade, são elas: Copa Baixio de Futebol de Campo, que é realizada de janeiro a abril; a Festa das Hortaliças, que geralmente acontece entre os meses de novembro ou dezembro. Em 2011, aconteceram nos dias 4 e 5 de novembro. Sendo uma das principais festas que a comunidade realiza, ela já está na sua quinta edição e a cada ano que passa leva mais turistas para a comunidade. Essa festa mobiliza toda a comunidade, entre homens, mulheres e crianças, todos participam ativamente para que tudo ocorra bem no dia da grande festa. Outra festa também importante é a festa da padroeira da ilha do Baixio, que é a festa de Santa Luzia, que acontece no mês de dezembro, com a realização de um arraial durante toda uma semana.

As mulheres ficam encarregadas com os serviços da cozinha e as também colaboram com ornamentação da ilha, e elas preparam suas mudas de plantas medicinais e também mudas de hortaliças para serem vendidas na festa; os homens ficam com a parte mais pesada, como construir as barracas e os serviços mais pesados, os jovens ficam responsáveis pelas maquetes da comunidade. Como a maioria dos moradores da comunidade é católica, a festa destina-se em prol da construção da Igreja. A festa é bastante divulgada pela imprensa e leva milhares de pessoas à comunidade, sobretudo agora com o término da construção da ponte, que liga Manaus a Iranduba e vice-versa, que tornou mais rápido o acesso à comunidade.

$\mathrm{Na}$ época das festas na comunidade, todos se reúnem em prol da comunidade, é o que relata dona Maria da Conceição da Cunha Cruz: 
Todo mundo se reúne quando tem festa na comunidade, todo mundo trabalha unido, chega o tempo do festival a gente se reúne e trabalha todo mundo, é uma comunidade, porque a comunidade é a união (Entrevista com dona Maria da Conceição da Cunha Cruz, comunidade Santa Luzia da ilha do Baixio, 14/9/2011).

\section{A ilha do Baixio e o desenvolvimento sustentável}

Para Schweickardt, o discurso em torno da noção de desenvolvimento sustentável, a despeito de sua ambiguidade, tem trazido à tona formas tradicionais e trabalho, agora tornadas visíveis com base numa economia de recursos naturais. Tratar a economia de grupos sociais da floresta pelo argumento da simplicidade é um reducionismo que mascara a complexidade de tais relações.

Uma análise mais cuidadosa das formas de cumprir um calendário agroextrativo, por parte das mulheres, dentro do qual se inclui a agricultura da mandioca e de outras raízes e frutos, a pesca e a caça, o manejo de espécies extrativas, coleta de sementes oleaginosas revelam formas de produção e de organização social interna complexas e singulares do ponto de vista social e cultural.

Nessa perspectiva, segundo Schweickardt (2010), construir um olhar mais interrogativo sobre o conjunto dos atores sociais da floresta, no interior da Amazônia, dando especial destaque à voz e à percepção das mulheres no processo produtivo na comunidade de Santa Luzia, pode nos tornar capazes de captar outras relações lógicas que nos ajudem a compreender como esses atores conseguem reinventar cotidianamente práticas de cuidar da vida, em situação, na maior parte das vezes, extremamente difíceis.

É como relata dona Maria Aparecida Aquino dos Santos, quando ela fala da dificuldade em relação à água que é utilizada para beber:

Aqui é um lugar excelente pra se morar, mas na seca o mais difícil aqui é a água, porque quando a gente não vai pegar no Iranduba e traz de ônibus e vem até em frente de casa quando está na seca, às vezes a pipa vem deixar a água, mas a água é muito ruim, essa pipa é da prefeitura. Agora melhorou porque tem um poço artesiano ali em cima e a 
gente pode pegar lá, hoje meu filho foi pegar lá. Não tomo a água do lago porque a gente se acostumou a tomar a água do poço, porque antes a gente usava o cloro, mas é difícil de conseguir, porque ele não é vendido (Entrevista com dona Maria Aparecida Aquino dos Santos, comunidade Santa Luzia da ilha do Baixio, 7/7/2011).

O desenvolvimento sustentável que, hoje, é o que mais se houve falar no momento, ainda deixa muito a desejar, só se houve falar, mas a maioria das pessoas não se preocupa em saber o que realmente significa o tão falado "desenvolvimento sustentável", principalmente quando se fala em Amazônia todos falam em preservação, desenvolvimento, mas não cumprem o que realmente se propõe a fazer, que é o progresso sem degradação para o meio ambiente e para as futuras gerações.

Por meio da pesquisa realizada na ilha do Baixio, percebe-se que os moradores da comunidade participam ativamente para o progresso da ilha, procurando sempre preservar o meio ambiente, pois algumas mulheres dizem que morar na comunidade é muito bom, porque já passaram, segundo elas, por momentos mais difíceis que hoje, como, por exemplo, a escola, a energia elétrica, as casas construídas pelo Incra, contribuíram para que eles levassem seu cotidiano sem pensar em sair da ilha.

Dona Rondineia expressa bem o que pensa em relação à comunidade, quando é perguntado para ela se algum dia já pensou em sair do Baixio:

Não, para morar em outro canto assim não, a gente tem vontade de desenvolver os estudos, mas a gente tem um sonho de ainda chegar aqui uma faculdade e a gente fazer, mas pra sair assim pra morar em outro canto eu não tenho vontade, a gente sai, passa uns dias para passear, mas pra morar muito tempo eu não tenho muita vontade não, eu penso muito na mudança, aqui acostumado a viver numa moradia calma e vai pra cidade é mais violência, tem as influências, a gente pensa em filhos, aí por esses motivos, pensando nisso a gente nunca saiu. Meu pai e minha mãe sempre incentivou a gente nos estudos, mas por todos esses motivos a gente nunca saiu daqui (Entrevista com dona Rondineia, comunidade Santa Luzia da ilha do Baixio, 7/7/2011). 
Segundo Lima (2005), ao contrário do que ocorre na maioria dos movimentos migratórios, na várzea não consta como causa direta da emigração a busca de trabalho ou de melhores rendimentos econômicos. Ao contrário, muitas vezes a mudança para a cidade acarreta no problema de como sobreviver.

Um dos pontos principais das propostas para o desenvolvimento da sustentabilidade na várzea seria focalizar melhorias nas condições de comercialização da produção, apoio técnico para agricultura, alternativas econômicas e a definição de programas de crédito e assistência técnica apropriada às condições de produção na várzea.

\section{Considerações finais}

Durante o segundo semestre da pesquisa, ao analisar a participação das mulheres no processo produtivo da ilha do Baixio a partir da percepção delas, conclui-se que as mulheres participam ativamente das atividades realizadas na comunidade. Elas participam tanto nos serviços domésticos como na agricultura, no cultivo das hortaliças, algumas trabalham na escola da comunidade como professoras, serviços gerais e administrativos, outras já são aposentadas, mas continuam ajudando a família na agricultura.

Ao decorrer da pesquisa, por meio de entrevistas realizadas com as mulheres da comunidade, pode-se notar a participação delas nas atividades sociais, como as festas realizadas na ilha, que tem uma das principais a Festa das Hortaliças, onde elas podem tanto vender as hortaliças cultivadas como também as plantas medicinais. Algumas famílias possuem canteiros suspensos para o consumo próprio, já que na época da cheia elas não têm como plantar. A pesca também é realizada durante o período da cheia e vazante, que, segundo elas, a maioria pesca tanto para o consumo próprio como para venda desses pescados.

Em entrevistas realizadas com as mulheres da comunidade, a maioria delas, apesar de exercerem outras funções, todas se identificam como agricultoras, elas ajudam no cultivo das hortaliças, tanto para consumo quanto para a venda, mas segundo elas só a venda das hortaliças não chegam a ter renda mensal de um salário mínimo, chegando a passar por dificuldades financeiras na época da cheia. Algumas delas relataram também que pescam 
durante a época da cheia e também na vazante, para o consumo, e algumas delas vendem o peixe para Manaus.

Com a implantação do Projeto de Assentamento Agroextrativista (PAE) do Incra, segundo algumas entrevistas realizadas com as mulheres da comunidade, elas relataram que ele trouxe benefícios para muitas famílias, como, por exemplo, casa própria para filhos casados e demais parentes que moravam juntos. As casas são em madeira, feitas para área de várzea, algumas com ar-condicionado, com a chegada da energia elétrica na comunidade, aproximadamente há dez anos, elas dizem que a vida melhorou bastante, também relataram que a vida na comunidade é muito boa, principalmente porque a escola agora tem o Ensino Médio que antes não tinha, que elas e nem seus filhos precisariam sair da comunidade para estudar, só quem quer prosseguir no Ensino Superior.

Antes da conclusão da ponte sobre o rio Negro, os agricultores sentiam dificuldades para trazer seus produtos para vender para Iranduba e Manaus, com a conclusão da ponte, segundo elas, irá facilitar o acesso das famílias para o município de Iranduba e Manaus para a comercialização das hortaliças.

\section{Referências}

AYRES, Márcio. As matas de várzea de Mamiraná: médio rio Solimões. Brasília: CNPq / Sociedade Civil Mamirauá, 1993.

FERRANTE, Vera Lúcia. Diretrizes Políticas dos mediadores: reflexões de pesquisas. In: MEDEIROS, Leonildes (Org.). Assentamentos rurais: uma visão multidicisplinar/organizadores. São Paulo: Editora da Universidade Estadual Paulista, 1994 (Prisma), p. 127-130.

HOMMA, A cultura de juta e malva na Amazônia: sementes de uma nova racionalidade ambiental? In: WITKOSCKI, Antônio Carlos, FERREIRA, Aldenor da Silva, HOMMA, Alfredo Kingo Oyama, FRAXE, Terezinha (Orgs.). A imigração japonesa no Estado do Amazonas: a expansão da juta no médio e baixo Solimões. São Paulo: Annablune, 2010, p. 39-41.

HOMMA, Alfredo Kingo. A imigração japonesa na Amazônia: contribuição na agricultura e vínculo com o desenvolvimento regional. In: HOMMA et. 
al. (Orgs.). Contribuição na Agricultura e Vinculo com o Desenvolvimento Regional. Introdução. Manaus: Edua, 2011, p. 27-30

PALMEIRA, Moacir. Burocracia, política e reforma agrária. In: MEDEIROS, Leonildes (Org.). Assentamentos rurais: uma visão multidicisplinar/organizadores. São Paulo: Editora da Universidade Estadual Paulista, 1994, p. 49-52.

PAULILO, Maria Ignez S. Movimentos das mulheres agricultoras e os muitos sentidos da "igualdade de gênero". In: MAÇANO, Bernardo; MEDEIROS, Leonilde S.; PAULILO, Maria Ignes (Orgs.). Lutas Camponesas Contemporâneas: condições, dilemas e conquistas. Vol. 2. São Paulo: Editora Nesp; Brasília: Núcleo de Estudos Agrários e Desenvolvimento Rural, 2009.

SCHWEICKARDT, Kátia Helena S. C. Projeto de Pesquisa Mulheres da Floresta: Memória, território e políticas públicas nas várzeas do Amazonas. Manaus: Ufam / CNPq, 2010.

SCHWEICKARDT, Kátia Helena S. C. Estratégias e territorialização na Amazônia contemporânea a partir dos parâmetros ambientais. In: OLIVEIRA, José Ademir (Org.). Espaços Urbanos na Amazônia: Visões geográficas. Manaus: Valer, 2011. 